\title{
TREATMENT OF OSTEOPOROTIC DISTAL RADIUS FRACTURES WITH VOLAR LCP : AN ORTHOPAEDIC CHALLANGE
}

\author{
M.S. DHANDA ${ }^{\mathrm{a}}$, H.S. MADAN ${ }^{\mathrm{b} 1}$, M.S. KAWADE ${ }^{\mathrm{c}}$, A.K. SAXENA ${ }^{\mathrm{d}}$, NARESH KUMAR ${ }^{\mathrm{e}}$ AND S. GOEL $^{\mathrm{f}}$

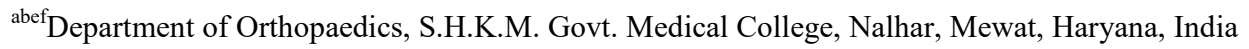 \\ ${ }^{\mathrm{d}}$ Department of Anatomy, S.G.T. Medical College, Gurgaon, Haryana, India \\ ${ }^{c}$ Department of Orthopaedics, Government Medical College, Nagpur, Maharashtra, India
}

\begin{abstract}
Distal radius fractures are challenging and always remain a matter of considerable interest and debate among orthopaedic surgeons. Osteoporosis increases the bone fragility and susceptibility of these fractures significantly especially in elderly females. Many treatment modalities have been developed from cast immobilization, percutaneous fixation, external fixation, open reduction and internal fixation to arthroscopic internal fixation. We analyzed results of volar LCP in osteoporotic distal radius fractures on restoring wrist motion and prevention of wrist stiffness. 25 osteoporotic patients from a period between January 2014 and December 2015 were treated with pre-contoured volar distal radius locking plating system. The patients were assesed prospectively about the outcome and the complications after an average follow up of 24 months in 25 patients treated using volar LCP in osteoporotic distal radius fractures. Excellent to good results were seen in 17 patients. The present study indicates that Volar LCP is a promising implant particularly for comminuted distal radius fractures with osteoporosis and provide reasonable subchondral support. It helps in maintenance of reduction in osteoporotic patients and prevent complications as well as early mobility enables to restore wrist motions near normal range.
\end{abstract}

KEYWORDS: Osteoporosis, Distal Radius Fractures, Volar LCP, Osteoporotic Radial Fractures, External Fixation, DVR Plates, Colles Fracture

Distal radius fractures are challenging and always remain a matter of considerable interest and debate among orthopaedic surgeons. Distal radius fractures account for almost every one in six cases reported in accident and emergency settings (Colles, 2006). Distal radius fractures, ranging from extra-articular Colles to severely comminuted fractures, always remain in controversy regarding best modality of treatment. Furthermore, the wide variety of treatment options are available to add on to the confusion. Over the years, several fracture classifications have also been developed. In addition to the diffculties due to change in the kinematics of radio-carpal and distal radio- ulnar joints, osteoporotic bone poses a significant challenge to the treating surgeon. The bone fragility (Meiners et. al., 2012), comminution and the bone purchase to the fixed implant are the issues which need to be handled gently and accurately.

To overcome all these issues, we operated these osteoporotic patients with distal radius fractures and fixed the fracture with precontoured volar locked plates (Orbay et. al., 2004) via modified approach of Henry. The advantages of volar plating and the additional stability by locking plate systems are now well known and their use enabled us to get excellent to fair results in our study. The benefit of bisphosphonates on the osteoporotic bone helped in healing process.

\section{MATERIALS AND METHODS}

25 patients with osteoporotic distal radius fractures were treated with pre-contoured volar locking plate system. Provisional reduction was achieved by either using external fixation or by traction ligamentotaxis under image intensifier with $\mathrm{K}$-wires. The fracture was approached by extended FCR approach of Henry (Schutz et. al., 2003) and pronator quadratues was stripped in L-shaped manner (Long Limb of $\mathrm{L}$ to be kept radially), then, fracture fragments were identified and reduced in position with small periosteal elevator and Hohmann's retractors gently. The distal Radio-carpal and Radio ulnar parameters were brought into the acceptable range with focus on palmar tilt. We tried to use only one cortical screw and rest all locking head screw to improve the purchase and to provide additional stability in the osteoporotic fractured fragments. The external fixator and K-wires were removed after plate fixation. Sometimes, one or two $\mathrm{K}$ wires may be left to provide better hold to small chip fragments which are not fixed with plates. The wound was closed in layers. (Images 1-3). Mobilization started at 72 hours after first dressing and the splint was removed 5 times a day for physiotherapy.

${ }^{1}$ Corresponding author 
Stitches removed at 2 weeks and splint removed at 6 weeks.Patients were followed at $2 \mathrm{wk}, 4 \mathrm{wk}, 6 \mathrm{wk}, 3$ month and then every 6 month for 2 year.

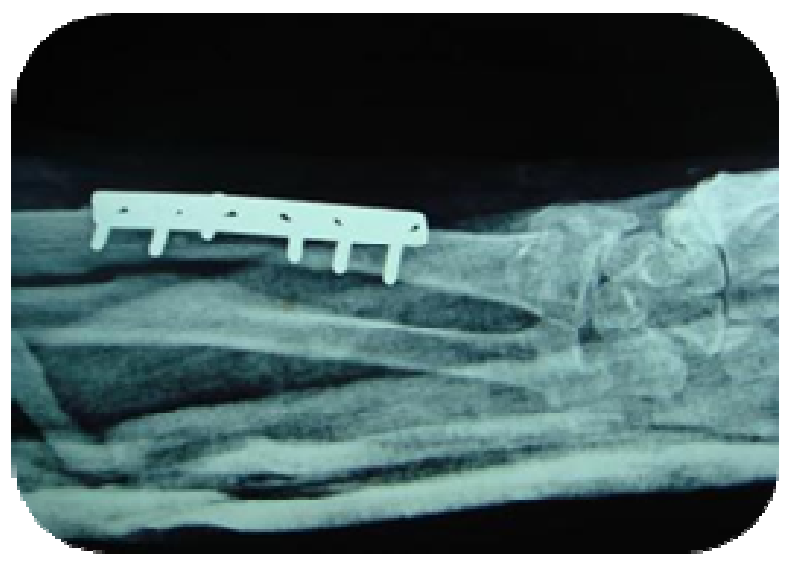

Image 1a: Preoperative AP

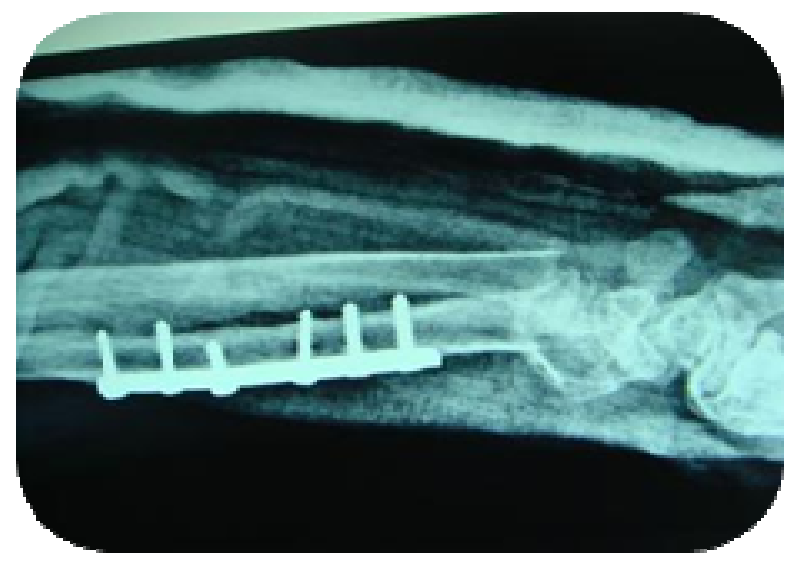

Image 1b: Preoperative Lateral

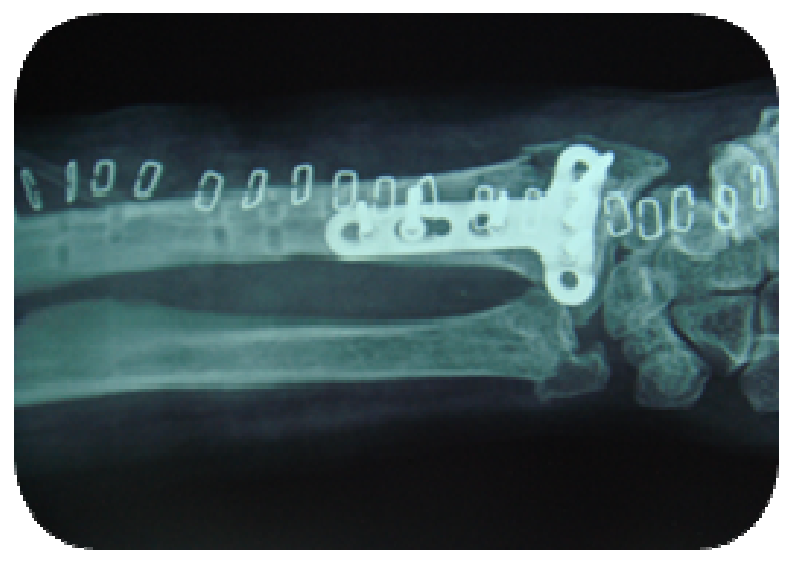

Image 2a: Postoperative AP

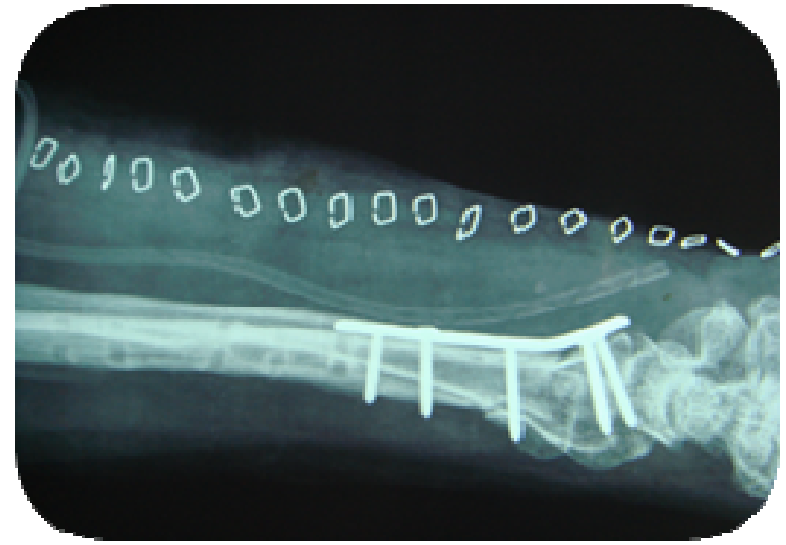

Image 2b: Postoperative Lateral

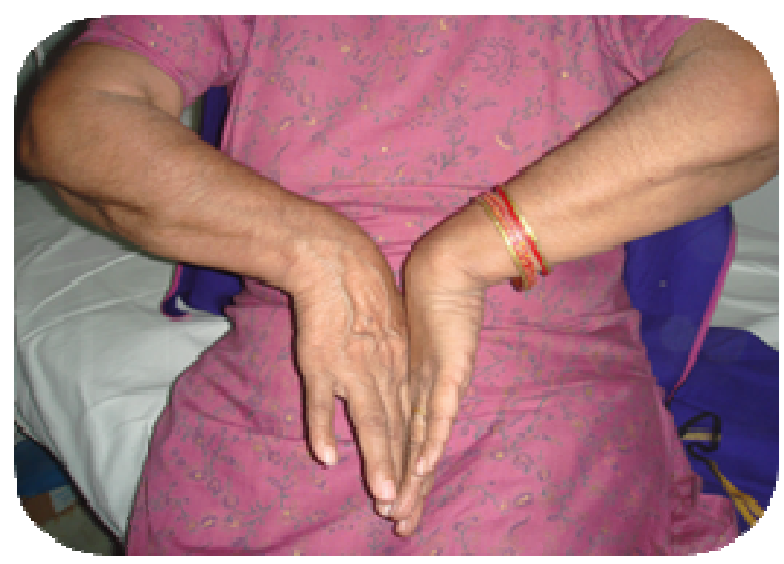

Image 3a: Clinical Picture

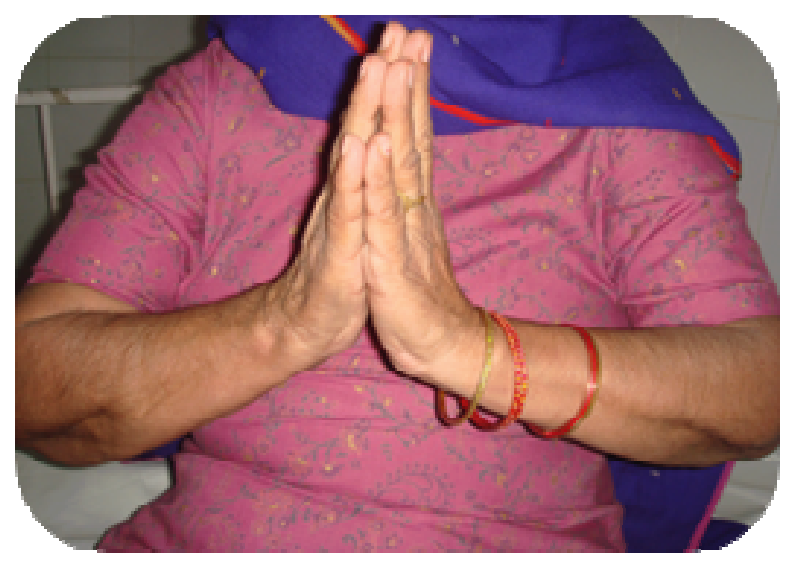

Image 3b: Clinical Picture

\section{OBSERVATIONS AND RESULTS}

25 cases were operated and evaluated over a period of 2 year. The Female to males ratio was 3:2. All fractures were classified by Frykman's (Frykman et. al., 
1967) classification (Type 1: 10, Type 2: 5, Type 3: 2, Type 5: 5, Type 7: 2, Type 8:1) and only those patients who had $<2.5$ SD score on DEXA scan were included in the study. Out of 25 cases, 14 patients had fall on outstretched hand and 11 patient got injured due to roadside accident. All patients were operated by volar approach and fixation done with pre-contoured volar locking plates. The functional results (Table 1) were calculated with the help of Demerit point system of Gartland and Werley (Gartland et. al., 1951) and the grip strength (Lidstrom, 1959) (Table-2) was measured using hand dynamometer. One patient had associated fracture of femur neck. The following outcome were observed.

Table 1: Gartland And Werley Scoring (Gartland et. al., 1951)

\begin{tabular}{|c|c|c|}
\hline Outcome & $\begin{array}{c}\text { Number of } \\
\text { Patients }\end{array}$ & Percentage \\
\hline Excellent (0 to 2) & 9 & 36 \\
\hline Good (3 to 8$)$ & 8 & 32 \\
\hline Fair (9 to 20) & 7 & 28 \\
\hline Poor (21 to 24) & 1 & 4 \\
\hline
\end{tabular}

Table 2- Grip Strength (Lidstrom, 1959)

\begin{tabular}{|l|c|c|c|}
\hline & $\begin{array}{c}\text { Excellent } \\
\mathbf{( 9 0 - 1 0 0 \% )}\end{array}$ & $\begin{array}{c}\text { Good } \\
(\mathbf{7 0 - 9 0 \% )}\end{array}$ & $\begin{array}{c}\text { Poor } \\
(<\mathbf{7 0 \%})\end{array}$ \\
\hline No of cases & 13 & 11 & 1 \\
\hline
\end{tabular}

One patient had superficial infection which subsided with antibiotics and serial aseptic dressings. One case (Frykman type-8) reported with screw pull out that needed a second surgery after 6 weeks. One patient had intra-articular screw placement which required removal of that locking head screw.

All patients were followed for two years and supplemented with oral bisphosphonates as anti-resoptive agents till 18-24 months.

\section{DISCUSSION}

Distal radius fractures remain an injury that fosters considerable interest and debate. Associated osteoporosis makes the task further difficult. Volar LCP is particularly useful in the prevention of secondary displacement of the unstable fractures in elderly with osteoporotic bone (Chan et. al., 2003) Interest in distal radius fracture stems not only from its high incidence but also from developing understanding of outcome variables and influence of technology in evaluation and treatment (Ilyas et. al., 2007). Trumble et al stated that the degree of articular step-off, gap between fragments, and radial shortening can be better corrected with surgery and correlates strongly with improved outcome (Colles, 2006). With the aim of restroration of articular surface and early finger and wrist mobilization, the present study was conducted with the use of volar LCP in osteoporotic fractures. Most surgeons now believe that open reduction with volar locked plates provides more stable fixation and allow earlier range of motion than percutaneous fixation does (Wong et. al., 2005). Leung et al reported that those who had been managed with plate fixation had a better cosmetic results and function at two years (Leung et. al., 1989).

\section{CONCLUSION}

Volar LCP is a promising implant for comminuted distal radius fractures with osteoporosis and provide reasonable subchondral support. It helps in maintenance of reduction in osteoporotic patients and prevent complications. Moreover, an early mobility enables to restore wrist motions near normal range. Our study showed that the Locked plate provide excellent fracture stability and pre-contouring give sufficient buttressing effect in the osteoporotic cortico-cancellous region. This construct along with early physiotherapy and bisphosphonates may provide an improved outcome. Though more studies are required to conclude a concrete outcome, nonetheless, the present study points that comminuted distal radial fractures in the elderly patients operated with volar locked plates, not only have good results but also reduces the chances of complications. The medical treatment of osteoporosis needs to be started concurrently for better outcomes along with the surgical interventions in such patients.

\section{REFERENCES}

Chan K.W., Kwok T.K. and Mak K.H., 2003. Early experience with locking compression plate in treatment of distal radisu fractures. Hongkong J. Orthop Surg., 7:88-93.

Colles A., 2006. On the fracture of the carpal extremity of the radius. Clin. Orthop Relat Res., 445:5-7.

Frykman G.K., 1967. Fracture of the distal radius, including sequelae of shoulder hand syndrome, disturbance of the distal radioulnar joint and impairment of 
DHANDA ET AL.: TREATMENT OF OSTEOPOROTIC DISTAL RADIUS FRACTURES WITH VOLAR LCP...

nerve function. Acta Orthop Scand Supplement, 108: 1 .

Gartland J.J. and Werley C.W., 1951. Evaluation of healed Colles fracture. J. Bone J. Surg., 33A: 895-907.

Ilyas M.A. and Jupiter B.J., 2007. Distal Radial FracturesClassification of Treatment \& Indication for surgery. Ortho Clin North America, 38:167-173.

Leung K.S., Shen W.Y. and Leung P.C., 1989. Ligamnetotaxis and bone grafting for comminuted fractures of the distal radius. J. Bone J. Surg., 71B:838.

Lidstrom A., 1959. Fractures of the distal end of the radius: A clinical and statistical study of end result. Acta Orthop Scan Suppl., 41.

Meiners J., Jurgens C., Maagerlein S., Wallstabe S., Kienast B. and Faschingbauer M., 2012. Osteoporotic fractures of the distal radius. What is new? Chirurg, 83:892-6.

Orbay J.L. and Fernandez D.L., 2004. Volar fixed-angle plate fixation for unstable distal radius fractures in the elderly patient. J. Hand Surg. Am., 29:96-102.

Schutz M., Kolbeck S., Spranger A., Arndt K.M. and Hass N.P., 2003. Palmar plating with the locking compression plate for dorsally displaced fractures of the distal radius- first clinical experiences. Zentralbl Chir., 128(12): 997-1002.

Wong K.K., Chan K.W., Kwok T.K. and Mak K.H., 2005. Volar fixation of dorsally displaced distal radius fractures using LCP. J. Orthop Surg., 13(2):153157. 